\title{
COMENTARIOS DEJURISPRUDENCIA
}

\author{
Comentario de sentencias del Tribunal Supremo relativas \\ a subvenciones que fueron concedidas por personas encausadas \\ en el proceso penal de los ERE
}

\section{Antonio Gayo Rubio}

Letrado de la Junta de Andalucía

\begin{abstract}
SUMARIO: I.- INTRODUCGIÓN; II. PLANTEAMIENTO Y CONTEXTO. III. SOBRE LA CADUCIDAD DE LOS EXPEDIENTES DE REVISIÓN DE OFICIO. 1. Circunstancias del caso; 2. Artículo 49. 1 de la Ley 30/1992; 3. Fundamento de las sentencias. "Las circunstancias aconsejan” la ampliación; 4. Dos consideraciones generales más que contienen las sentencias acerca de los expedientes de revisión de oficio y sobre la ampliación de plazos; 5. Valoración. IV. ARTÍCULO 106 DE LA LEY 30/1992. LÍMITES A LA REVISIÓN DE OFICIO. 1. Circunstancias del caso; 2. Nulidad de pleno derecho de las subvenciones revisadas de oficio; 3. Límites de la revisión de oficio (artículo 106 Ley 30/1992) Transcurso de cuatro años; 4. Fundamentos de las sentencias; 5. Examen de los límites de la buena fe y del principio de confianza legítima. V. CONCLUSIÓN.
\end{abstract}

\section{INTRODUCGION.}

La Sala Tercera del Tribunal Supremo ha dictado recientemente las sentencias de 21-XII-2016, 11-I-2017, 4-V-2017, 11-V-2017 y 13-VI-2017 que merecen ser comentadas por diversas razones.

En primer lugar, porque contienen un importante análisis de la estructura, alcance y efectos del artículo 106 de la Ley 30/1992 que establece los límites a la revisión de oficio y sobre el que no existía suficiente doctrina jurisprudencial hasta el momento.

En segundo lugar, porque la doctrina que sientan acerca de los artículos 102 y 106 de la Ley 30/1992 resulta plenamente aplicable a los artículos 106 y 110 de la nueva Ley 39/2015, de 1 de octubre, del Procedimiento Administrativo Común de las Administraciones Públicas, en los que se regula actualmente la revisión de oficio de manera casi idéntica.

En tercer lugar, porque examinan los efectos de la declaración de nulidad de actos administrativos concretos como son las subvenciones, previstos en una norma 
especial que es el artículo 36. 4 de la Ley 38/2003, de 17 de noviembre, General de Subvenciones.

En cuarto lugar, porque contienen también interesantes pronunciamientos acerca de la ampliación del plazo de resolución de los expedientes administrativos contemplada en el artículo 49. 1 de la Ley 30/1992 (actual artículo 32. 1 de la Ley 39/2015, de 1 de octubre, del Procedimiento Administrativo Común de las Administraciones Públicas) así como sobre la caducidad de los expedientes de revisión de oficio, la cual no se produce por el transcurso del plazo establecido sin resolver y notificar a los interesados como el resto de expedientes administrativos en general, sino tan sólo por el transcurso de dicho plazo sin dictar la resolución que ponga fin al expediente.

Y en quinto lugar, estas sentencias merecen ser divulgadas porque permiten conocer el desenlace de un episodio del llamado escándalo de los ERE fraudulentos de Andalucía que, por haberse ventilado ante la jurisdicción contencioso-administrativa, no ha recibido el mismo tratamiento mediático que las resoluciones de los juzgados de instrucción o las operaciones policiales que abren a diario los noticiarios, como ha ocurrido también a lo largo de la instrucción penal seguida por el Juzgado de Instrucción $n^{\circ} 6$ de Sevilla en este caso.

Estas cinco sentencias contienen las primeras decisiones adoptadas por el Tribunal Supremo acerca de la revisión de oficio por la Junta de Andalucía de las subvenciones concedidas ilegalmente durante el periodo 2000-2010 por quien ocupaba el cargo de Director General de Trabajo y Seguridad Social de la Consejería de Empleo y es el principal imputado en dicha causa.

Esta extraordinaria tarea de revisión de oficio, desarrollada a través de más trescientos expedientes, y que comenzó en el año 2012 con el fin de recuperar en torno a 92 millones de euros que salieron indebidamente de las arcas públicas autonómicas, comienza a verse confirmada al fin por el Tribunal Supremo que concluye, en contra de lo dispuesto por la Sala de lo contencioso-administrativo del Tribunal Superior de Justicia de Andalucía en la instancia, que los beneficiarios de las subvenciones ilegales tienen la obligación de devolverlas.

Por tanto, trascendiendo de la concreta doctrina que contienen acerca de la revisión de oficio y de la ampliación de plazos, el comentario de estas sentencias resulta especialmente obligado en un momento como el presente en el que tantos casos de corrupción se están descubriendo relacionados con las Administraciones públicas en nuestra patria y con ocasión de los cuales se inician diversas vías ante jurisdicciones diferentes. 
Las sentencias vienen a demostrar con un ejemplo de plena actualidad que, sin perjuicio del resultado de las causas penales que puedan seguirse también por los mismos hechos y que son las que captan la atención de la masa, el Derecho administrativo es el que contiene los recursos ordinarios y más eficaces para recuperar en estos casos los fondos públicos defraudados, debiendo seguir conservando el Derecho penal para que sea verdaderamente útil su consideración de última ratio.

\section{PLANTEAMIENTO Y CONTEXTO.}

Tras descubrirse el llamado fraude de los ERE y denunciarse los hechos ante la jurisdicción penal, la Consejería de Empleo de la Junta de Andalucía en el año 2012 inició una extraordinaria tarea de revisión de oficio de las subvenciones concedidas por Francisco Javier Guerrero Benítez durante el tiempo en que fue Director General de Trabajo y Seguridad Social pues se pudo comprobar que tales subvenciones habían sido concedidas prescindiendo total y absolutamente del procedimiento legalmente establecido.

Las subvenciones concedidas con cargo a la famosa partida presupuestaria $31 \mathrm{~L}$, conocida en los medios como el "fondo de reptiles", que fueron revisadas de oficio en virtud de las órdenes de la Consejería impugnadas en los recursos contencioso-administrativos cuyas sentencias se comentan, estaban siendo investigadas también a través de las Diligencias Previas 174/2011 del Juzgado de Instrucción no 6 de Sevilla.

Fueron tramitados más de trescientos expedientes de revisión de oficio que en su gran mayoría concluyeron mediante resoluciones en virtud de las cuales se declaró que las subvenciones eran nulas de pleno derecho por haber prescindido total y absolutamente del procedimiento legalmente establecido (artículo 62. 1 e) Ley 30/1992). Dichas resoluciones contenían también un segundo apartado en el que se acordaba que, en consecuencia, debía exigirse a cada beneficiario el reintegro de lo percibido en virtud de lo dispuesto en el artículo 36. 4 de la Ley 38/2003, de 17 de noviembre, General de Subvenciones, que dispone que: "La declaración judicial o administrativa de nulidad o anulación llevará consigo la obligación de devolver las cantidades percibidas".

Muchas de las empresas que percibieron aquellas subvenciones acudieron a la jurisdicción contencioso-administrativa para impugnar las citadas resoluciones, recayendo el conocimiento de todos los recursos, excepto uno del que conoció la Sede de Málaga, en la Sección $1^{a}$ de la Sede de Sevilla de la Sala de lo contencioso-administrativo del Tribunal Superior de Justicia de Andalucía. Solamente la sentencia dictada en Málaga condenó a la beneficiaria a devolver la subvención.

El resultado de aquellos recursos contencioso-administrativos (más de cincuenta) fue siempre favorable para los beneficiarios recurrentes por dos motivos. 
Por una parte, las sentencias recaídas en recursos en los que se enjuiciaron expedientes de revisión de oficio en que se acordó por la Consejería la ampliación del plazo para resolver al amparo del artículo 49. 1 de Ley 30/1992 declararon que los mismos habían caducado.

Otro grupo de sentencias estimaban parcialmente los recursos porque entendían que, si bien la subvención, en efecto, era nula de pleno derecho y, por tanto, la revisión de oficio debía ser confirmada, sin embargo, el segundo acuerdo que también contenían las resoluciones impugnadas mediante el que se acordaba que el beneficiario devolviese la subvención percibida, debía ser anulado con fundamento en el artículo 106 de la Ley 30/1992, porque "los efectos de la nulidad declarada (que es imprescriptible) deben quedar atemperados por razones de seguridad jurídica".

\section{SOBRE LA CADUCIDAD DE LOS EXPEDIENTES DE REVISIÓN DE OFICIO.}

\section{Gircunstancias del caso.}

El artículo 102. 5 de la Ley 30/1992, vigente cuando fueron tramitados los expedientes de revisión de las subvenciones, establecía un plazo de tres meses que resultaba muy breve para tramitar un expediente de la complejidad de la revisión de oficio. Además para hacerse una idea de la magnitud de la tarea de revisión de oficio que se llevó a cabo con ocasión del caso de los ERE debe comenzarse recordando, en primer lugar, que todas las subvenciones que tenían que revisarse habían sido concedidas por la misma Dirección General de Trabajo y Seguridad Social, lo que significaba que la totalidad de las revisiones le correspondía a la actual Consejería de Empleo, Empresa y Comercio, sobre la que recayó de repente una tarea extraordinaria adicional y muy urgente que debía afrontar con los medios que tenía asignados para la gestión ordinaria de los asuntos de su competencia.

Además debe tenerse en cuenta la existencia ya por aquel entonces de una "macrocausa" penal abierta por el Juzgado de Instrucción n 6 de Sevilla en la que se investigaba no sólo la concesión de estas subvenciones sino toda la actividad desarrollada por el citado Director General así como también investigaciones de la Cámara de Cuentas y procedimientos ante el Tribunal de Cuentas cuyos numerosos y frecuentes requerimientos de documentación también tenían que ser atendidos con apremio por el mismo personal de la Consejería.

Otra importante circunstancia que dificultaba la tramitación de estos expedientes es que no sólo había que recabar el dictamen del Consejo Consultivo de Andalucía, sino también, el del Gabinete Jurídico de la Junta de Andalucía, de conformidad con el artículo 78. 2. e) del Reglamento de Organización y Funciones del 
Gabinete Jurídico de la Junta de Andalucía y del Cuerpo de Letrados de la Junta de Andalucía, aprobado por el Decreto 450/2000, de 26 de diciembre, que establece que habrá de ser consultado preceptivamente en "expedientes para la revisión de oficio de disposiciones y de actos administrativos nulos". Su solicitud aun pudiendo ser suspendido el plazo de resolución por el órgano competente, supuso un consumo de plazos adicional del procedimiento.

Asimismo la falta de medios humanos disponibles y la complejidad en la notificación de muchas empresas ya desaparecidas o con cambios de domicilio, dado el tiempo transcurrido desde la concesión de las ayudas, motivó que en el caso de un número importante de expedientes fuese necesario incluso tramitarlos en dos ocasiones pues se dio la circunstancia de haber transcurrido el plazo de tres meses sin que hubiese recaído resolución.

Como medida extraordinaria se dictó incluso una Resolución del Viceconsejero de Economía, Innovación, Ciencia y Empleo, encomendando a 22 funcionarios, en virtud del artículo 73.2 de la Ley 7/2007, de 12 de abril, del Estatuto Básico del Empleado Público, tareas de apoyo al Servicio de Ordenación y Coordinación Laboral para la instrucción de los expedientes de revisión de oficio relativos a las resoluciones dictadas por la extinta Dirección General de Trabajo y Seguridad Social.

\section{Artículo 49. 1 de la Ley 30/1992.}

Todo lo anterior justificaba sobradamente que se recurriese por la Consejería a la ampliación al amparo del artículo 49 Ley 30/1992 (actual artículo 32.1 de la Ley 39/2015, de 1 de octubre, del Procedimiento Administrativo Común de las Administraciones Públicas), que establece que "La Administración, salvo precepto en contrario, podrá conceder de oficio o a petición de los interesados, una ampliación de los plazos establecidos, que no exceda de la mitad de los mismos, si las circunstancias lo aconsejan y con ello no se perjudican derechos de tercero. El acuerdo de ampliación deberá ser notificado a los interesados”.

Conviene precisar que mientras la Ley 30/1992 exigía mayores requisitos para la ampliación al amparo del artículo 42. 6, pues en virtud del mismo era posible ampliar el plazo de duración de un expediente por un periodo igual al inicial ampliado, el artículo 49 es una norma que sólo permite la ampliación por un periodo que no supere la mitad del plazo que se amplía. En el presente caso no se aplicó el artículo 42. 6 pues el motivo de la ampliación no se encontraba en "el número de las solicitudes formuladas" (se trata de un expediente iniciado de oficio en el que no hay solicitudes) ni en el número de "las personas afectadas" (la única interesada en el expediente es la entidad beneficiaria de la subvención). Por ese motivo tampoco resultaba exigible 
a la Administración que antes de recurrir a la ampliación del plazo habilitase "los medios personales y materiales para cumplir con el despacho adecuado y en plazo".

El artículo 49. 1 sólo exige: a) que no haya un precepto que lo impida ("salvo precepto en contrario"); b) que la ampliación del plazo "no exceda de la mitad de los mismos" (se ha ampliado por un mes y quince días); c) que se aplique "si las circunstancias lo aconsejan" (motivo que queda a criterio de la Administración); y d) si "con ello no se perjudican derechos de tercero", extremo éste que ni siquiera había sido alegado por los beneficiarios recurrentes.

La Consejería consideró necesario ampliar el plazo de tres meses por otro mes y medio, resultando un plazo total de cuatro meses y medio. Los motivos empleados fueron tres, según los casos: a) "debido al volumen de expedientes de revisión de oficio que se tramitan en la Dirección General así como la necesidad de solicitar dos informes preceptivos para la resolución de dichos expedientes" (examinado por la STS de 21-XII-2016), b) por "las dificultades que ha encontrado esta Administración en la práctica de la notificación del trámite de audiencia, así como la obligación de peticiones de informes y dictámenes preceptivos" (examinado por la STS 11-V-2017), o bien c) "por coincidir el mes de agosto dentro del periodo establecido para resolver y notificar el presente procedimiento y tratarse de una época vacacional que dificulta el cumplimiento de los trámites de notificación y vista del expediente por parte de los interesados" (STS de 13-VI-2017)

Como se ha expuesto más arriba, sin embargo, ninguna de las sentencias de la Sala de lo contencioso-administrativo del TSJA dictadas con anterioridad a los pronunciamientos del Tribunal Supremo comentados en este artículo, consideró justificada la ampliación de los plazos acordada por la Consejería. La primera de las sentencias del Tribunal Supremo que aborda esta cuestión es la de 21-XII-2016 (recurso 312/2015, Sección Cuarta) y la misma no sólo declara que el expediente no estaba caducado sino que desestima en su totalidad el recurso interpuesto por la beneficiaria de la subvención, y obliga a devolver una subvención de 1.200.000 euros concedida en 2004 a una sociedad del entramado de empresas de la Sierra Norte de Sevilla - territorio en donde se concentró la mayor parte de las subvenciones concedidas ilegalmente- y cuyos propietarios eran también dos de los principales imputados en la causa penal, lo cual dio lugar a que se pronunciase también acerca de los límites a la revisión de oficio como luego será expuesto.

\section{Fundamento de las sentencias. "Las circunstancias aconsejan" la ampliación.}

Los argumentos ofrecidos ante el TSJA por la representación procesal de la Administración autonómica en los sucesivos procesos sustanciados para defender la 
ampliación del plazo de duración del procedimiento fueron variados y en buena parte se encuentran recogidos en las Sentencias del Tribunal Supremo de 21-XII-16, $11-\mathrm{V}-17$ y $13-\mathrm{VI}-17$.

Llama la atención la sencillez con la que el Tribunal Supremo, tras una exhaustiva argumentación, zanjó años de debate dando la razón a la Junta de Andalucía. En su fundamentación expone cuáles son los requisitos exigidos por el artículo 49 Ley 30/1992 para la ampliación, a continuación analiza la concreta motivación ofrecida en el expediente administrativo y por último concluye que la misma es suficiente no sólo por lo que en el acuerdo de ampliación se dice ("por la motivación expresada en el acto administrativo"), es decir, que se trata de "actuaciones y ayudas concedidas por la anterior Dirección general de Trabajo y Seguridad Social", sino porque su titular -como recoge la sentencia que se indicó en el escrito de interposición (de recurso de casación) de la Junta de Andalucía- "es el principal imputado en el proceso penal que comúnmente se conoce como "caso de los ERE". La sentencia para completar su decisión añade que dicha circunstancia goza de "notoriedad, que comporta una evidencia sabida por todos". Para la sentencia del TS, "además de la motivación expresada en el acto administrativo" "resulta(n) de singular relevancia en este caso las referencias señaladas que enmarcan este caso y [que] llevan a la conclusión de que la ampliación del plazo está justificada y motivada".

La motivación contenida en el acto reunía los elementos exigidos por los artículos 54. 1 y 49. 1 de la Ley 30/1992 que permiten conocer al interesado las concretas razones por las que se había acordado la ampliación del plazo, siendo el respeto de esta garantía el único objeto susceptible de control jurisdiccional. El único control que resulta posible en este caso es el que permite examinar si los motivos ofrecidos son acordes al fin legítimo del acto administrativo. La sentencia revocada, sin embargo, tras comprobar que el acto contenía una motivación concreta que exteriorizaba las razones que justificaron la decisión de ampliar, extendió indebidamente su revisión al contenido mismo de la decisión discrecional que está reservada por el legislador a la Administración que instruye el expediente, dejándole que sea ésta la que determine o aprecie cuáles son las "circunstancias que lo aconsejan".

Como expone la sentencia de 21-XII-2016, "la citada norma señala como presupuesto de la ampliación que "las circunstancias lo aconsejan y con ello no se perjudican derechos de tercero". De modo que son las circunstancias del caso las que han de inspirar o determinar la ampliación del plazo y de ellas, naturalmente, ha de dejarse constancia en el acto administrativo que acuerda tal ampliación. Ni que decir tiene, dicho sea de paso, que la mercantil recurrida no puede invocar su condición de tercero afectado en sus derechos, porque es interesado en el procedimiento administrativo y no un tercero". La sentencia se refiere a otra sentencia anterior del mismo Supremo, cuando dice: "En este sentido se viene pronunciando nuestra jurisprudencia, pues hemos considerado que se encontraba motivada la ampliación de plazos, en Sentencia de 18 de octubre de 2006 
(recurso de casación $\left.n^{\circ} 331 / 2004\right)$ cuando atendía, en un procedimiento sancionador, al "volumen y complejidad del expediente, que resulta de la abundante documentación unida al mismo (XXI tomos)", que fue considerado por la sentencia como un "factor de suyo relevante".

En el mismo sentido también se han pronunciado las Sentencias de 11-V-2017 (Recurso de casación 1824/15) y 13-VI-2017 (recurso de casación 288/2015), en las que se enjuiciaron otros acuerdos de ampliación basados en otros motivos pero que el Tribunal Supremo estimó ajustados a derecho por encontrarse adecuadamente motivados y por referirse también al caso de los ERE.

\section{Dos consideraciones generales más que contienen las sentencias acerca de los expedientes de revisión de oficio y sobre la ampliación de plazos.}

En primer lugar, en la STS 21-XII-2016 (FD Quinto) se aclara que el artículo 49 Ley 30/1992 permite la ampliación tanto del plazo total del expediente como de plazos de trámites concretos dentro del mismo, que fue otro motivo que permitió a la Sala TSJA estimar por caducidad los primeros recursos de los que conoció. "QUINTO.- (...) la aplicación del artículo 49.1 de la Ley $30 / 1992$ puede extenderse también al plazo para resolver, como hemos declarado en Sentencia de 20 de marzo de 2007 (recurso contencioso administrativo $\left.n^{\circ} 348 / 2005\right)$ que desestimó un alegato similar al que esgrime la recurrida en casación y recurrente en la instancia, sobre su compatibilidad o no con el artículo 42.6 de la misma Ley, al señalar <<tal como propone el Abogado del Estado. No puede aceptarse la interpretación realizada por la actora respecto a que la posibilidad de ampliación de plazos contemplada en el artículo 49 de la Ley 30/1992 no pueda ser aplicada al plazo máximo de duración de un procedimiento. Ni tal exclusión se establece de manera directa y expresa en el precepto señalado (a diferencia de lo que ocurría con anterioridad a la reforma de la Ley operada en 1.999), ni existen razones para deducirla en un análisis sistemático de la Ley. En efecto, la regulación específica para ampliar el plazo máximo de resolución y notificación de un procedimiento en el artículo 42.6 no obsta a la aplicación de la previsión genérica del artículo 49 al mismo supuesto, teniendo ambos preceptos un alcance diferente. Así, las condiciones para la aplicación del supuesto específico del artículo 42.6 son más estrictas y la ampliación puede alcanzar hasta un lapso de tiempo igual al del plazo máximo del procedimiento (artículo 42.6, párrafo tercero); por el contrario, la ampliación posible en aplicación de la previsión genérica del artículo 49 puede ser acordada por el propio órgano instructory sólo puede llegar hasta la mitad del plazo ampliado (apartado 1). >>"

En segundo lugar, la Sentencia de 11-V-2017 también precisa el cómputo de la caducidad en los expedientes de revisión de oficio que es diferente del resto de expedientes administrativos ("Es la fecha de la resolución, y no la de su notificación, la que determina la finalización del plazo de duración del procedimiento, y habiéndose dictado antes de superar el máximo, quedó enervado el efecto de caducidad del procedimiento. En este sentido se ha pronunciado esta Sala en sentencia de 18 de marzo de 2008 (rec. cas. núm. 2699/2005), resal- 
tando la diferencia entre el régimen general de la caducidad previsto en el art. 44.1 de la LPAC, que establece que el transcurso del plazo máximo sin haberse dictado y notificado la resolución producirá la caducidad, y el del procedimiento de revisión, para el que rige lo dispuesto en el art. 102.5 de la $L P A C$, que anuda el efecto de la caducidad al transcurso del plazo máximo de tres meses sin haberse dictado la resolución")

\section{Valoración.}

Las sentencias revocadas por el Tribunal Supremo obligaban a la Administración a tramitar de nuevo expedientes de revisión de oficio de ayudas millonarias de las que incluso existían indicios de haber sido obtenidas mediante la comisión de un delito y que, incluso asumiendo la tesis contenida en las sentencias revocadas, podrían entenderse caducados tan sólo por pocos días. Ello encuentra poca justificación si se tiene en cuenta que la acción de revisión de oficio por la Administración no prescribe y permitiría iniciarlos nuevamente cuantas veces fuese necesario.

Las sentencias del Tribunal Supremo tienen el enorme valor de haber apreciado todas las circunstancias que concurrían en el caso presente y que aconsejaban la ampliación del plazo de duración del expediente como prevé el artículo 49. El Tribunal Supremo da la razón a la Junta de Andalucía porque no considera posible sustraerse -como hicieron las sentencias recurridas- a las circunstancias tan extraordinarias que presentaba este "caso de los ERE" y que además de figurar en el mismo acto administrativo y de haber sido recordadas al tribunal en el recurso contencioso-administrativo son notorias. Y es que el caso ha creado suficiente alarma como para que se tenga en cuenta que a través del expediente se trataba de recuperar por la hacienda pública una subvención millonaria concedida por un antiguo Director General que se encuentra imputado por esos mismos hechos.

Y es que como se advertía a la Sala en el recurso de casación por la representación de la Junta de Andalucía, si en el caso enjuiciado no se consideraba que "las circunstancias aconsejan" la ampliación del plazo de resolución del expediente de revisión de oficio, difícil será encontrar (y esperemos que no tenga lugar de nuevo) otro supuesto de la realidad que justifique tanto su aplicación como el caso de corrupción que lamentablemente lo ha motivado descubierto en el seno de la Administración autonómica andaluza.

Precisamente, uno de los pocos cambios introducidos en la reforma del procedimiento administrativo por la Ley 39/2015, de 1 de octubre, del Procedimiento Administrativo Común de las Administraciones Públicas, se refiere a la duración del plazo para tramitar el expediente de revisión de oficio que ha pasado a ser ahora de seis meses (artículo 106. 5). Se ha venido así a reconocer por el propio legislador que el plazo de tres meses de la Ley 30/1992 (reforma de 1999) que regía cuando se 
revisaron las subvenciones, y que la Junta de Andalucía consideró necesario ampliar, era notablemente insuficiente.

\section{ARTÍGULO 106 DE LA LEY 30/1992. LÍMITES A LA REVISIÓN DE OFICIO.}

\section{Gircunstancias del caso.}

Otras sentencias recurridas en casación que no declaraban la caducidad del expediente de revisión de oficio estimaron parcialmente los recursos en la instancia porque entendían que si bien la subvención era nula de pleno derecho el segundo acuerdo que también contenían las resoluciones impugnadas mediante el que se acordaba que el beneficiario devolviese la subvención percibida debía ser anulado con fundamento en el artículo 106 de la Ley 30/1992, porque "los efectos de la nulidad declarada (que es imprescriptible) deben quedar atemperados por razones de seguridad jurídica".

Tales razones se encontraban en el transcurso de más cuatro años entre la fecha de obtención de las subvenciones y el inicio de los expedientes de revisión de oficio. El motivo empleado para anular el apartado que acordaba la devolución de la subvención era que "tanto la Ley General de Subvenciones (artículo 39), como la Ley General Presupuestaria o la Ley de la Hacienda Pública Andaluza, establecen un plazo de cuatro años de prescripción, que ha sido superado con creces, por lo que los efectos de la nulidad declarada (que es imprescriptible) deben quedar atemperados por razones de seguridad juridica".

En realidad de nada sirve que se confirme que una subvención es nula de pleno derecho y que su revisión de oficio es ajustada a derecho si se concluye que no hay que devolverla.

En la decisión de los recursos resueltos en instancia esta decisión se reiteró llegando a ser irrelevante incluso que se advirtiese por la representación procesal de la Junta de Andalucía al comienzo de los procesos judiciales que los propios beneficiarios recurrentes en algunos casos se encontraban imputados en la causa penal al igual que el Director General que concedió la subvención, o que en dicha causa penal se hubiesen impuesto a dichos beneficiarios importantes fianzas millonarias, a los efectos de demostrar que la revisión de oficio de las ayudas no era contraria al límite de la buena fe. oficio.

\section{Nulidad de pleno derecho de las subvenciones revisadas de}

Todas las sentencias recurridas coincidieron en que las subvenciones revisadas eran nulas de pleno derecho porque se habían dictado prescindiendo del procedi- 
miento legalmente establecido (artículo 62. 1. e) Ley 30/1992). No se hicieron excepciones pues como se concluía en muchas sentencias de la Sala del TSJA la causa de nulidad era "inequívoca". Las sentencias coincidían en que "la legalidad ha quedado gravemente afectada" y que "se prescindió total y absolutamente del procedimiento legalmente establecido" pues "es lo cierto que ni existió solicitud de ayuda y las resoluciones de concesión (...) se han adoptado sin procedimiento alguno".

La declaración de nulidad de pleno derecho de un acto administrativo se caracteriza por producir efectos ex tunc, porque el acto nulo nunca produce efectos. En cambio, la anulabilidad produce efectos ex nunc, es decir, a partir del momento en que se declara, siendo válidos los efectos producidos hasta ese momento. En el caso de actos nulos de pleno derecho, la aplicación de los límites del artículo 106 impide la revisión en sí del acto pero, desde luego, no permite la restricción tan sólo de los efectos de la revisión de oficio. Ello se debe a que los actos nulos de pleno derecho se diferencian de los actos meramente anulables en que no resulta posible su subsanación y en la eficacia ex tunc de la declaración de nulidad.

\section{Límites de la revisión de oficio (artículo 106 Ley 30/1992) Transcurso de cuatro años.}

Afirma la jurisprudencia (Sentencias de 13 y 27-III-2012 y 17-I-2006) que el ordenamiento jurídico español contempla en el artículo 106, junto a la revisión de oficio del artículo 102 LPG, "una solución contraria a la efectividad de la nulidad y que debe ser aplicada en función de las circunstancias presentes en cada caso", y que encuentra su fundamento en dos exigencias contrapuestas que en dichas sentencias se concretan: "el principio de legalidad, que postula la posibilidad de revocar actos cuando se constata su ilegalidad, y el principio de seguridad jurídica, que trata de garantizar que una determinada situación jurídica que se presenta como consolidada no pueda ser alterada en el futuro. El problema que se presenta en estos supuestos es satisfacer dos intereses que son difícilmente conciliables, y la solución no puede ser otra que entender que dichos fines no tiene valor absoluto. La única manera de compatibilizar estos derechos es arbitrando un sistema en el que se permita el ejercicio de ambos. De ahí que en la búsqueda del deseable equilibrio el ordenamiento jurídico sólo reconozca la revisión de los actos en concretos supuestos en que la legalidad se ve gravemente afectada y con respeto y observancia de determinadas garantías procedimentales en salvaguarda de la seguridad jurídica y todo ello limitando en el tiempo el plazo para ejercer la acción, cuando los actos han creado derecho a favor de terceros".

Es importante aclarar algo que puede pasar por alto en la lectura del artículo 106 de la Ley 30/1992 pero que ayuda a la hora de interpretarlo y es que en su estructura se distinguen por un lado una serie de presupuestos ("por prescripción de acciones, el tiempo transcurrido u otras circunstancias") que justifican a su vez la aplicación de los "límites" propiamente dichos al ejercicio de las facultades de revisión que se enumeran 
de forma tasada también en el precepto (que "su ejercicio resulte contrario a la equidad, a la buena fe, al derecho de los particulares o a las leyes").

La mera prescripción de acciones a la que se alude en las sentencias revocadas por el Tribunal Supremo no es un "límite" a las facultades de revisión sino un "presupuesto" que, de apreciarse, permitiría valorar si en el caso concreto concurren o está justificada la apreciación de alguno o algunos de los "límites" propiamente dichos al ejercicio de las facultades de revisión de oficio.

En los casos en los que se ha pronunciado el Tribunal Supremo con ocasión de las subvenciones revisadas por la Consejería de Empleo lo que era evidente es que no se había podido producir ni siquiera el presupuesto de la prescripción de las acciones de revisión que se mencionaba, por dos motivos. En primer lugar porque la acción de revisión por nulidad es imprescriptible (artículo 102. 1 Ley 30/1992 y artículo 106. 1 Ley 39/2015) y, en segundo lugar, porque en cualquier caso, el plazo de prescripción comenzaría a computarse desde que la nulidad fuese declarada y se pudiese exigir el reintegro correspondiente.

En cualquier caso, deja claro el Tribunal Supremo que el transcurso de un plazo de cuatro años tampoco es una circunstancia que permita apreciar la existencia de un límite a la revisión de oficio y, en segundo lugar, que el tribunal de instancia tenía que haber razonado sobre las razones excepcionales relacionadas con la equidad, buena fe o derechos de los particulares que se verían afectados por la nulidad del acto declarado.

Y como se ha dicho con anterioridad, si por un lado se confirma la nulidad de la subvención difícilmente se puede suprimir el único efecto que la misma ha producido y que es su percepción por el beneficiario.

\section{Fundamentos de las sentencias.}

Expuesta en síntesis la doctrina del Tribunal Supremo sobre la aplicación de los límites del artículo 106 Ley 30/1992, por su enorme claridad resulta oportuno reproducir los términos exactos en los que se pronuncia la Sentencia de 11-I-2017 (recurso 1934/2014) Mediante aquella revisión de oficio se declaró la nulidad de una subvención a otra empresa por importe de tres millones de euros.

"SEGUNDO. (...) Partiendo de que la revisión de oficio de un acto nulo de pleno derecho se puede realizar en cualquier momento y, por tanto, se trata de una acción imprescriptible, hay que tener en cuenta que el art. 106 de la Ley 30/1992, de 26 de noviembre establece una cláusula de cierre que limita la posibilidad de revisión en supuestos excepcionales, al disponer que $<<$ las facultades de revisión no podrán ser ejercitadas cuando por prescripción de acciones, por el tiempo 
transcurrido o por otras circunstancias su ejercicio resulta contrario a la equidad, a la buena fe, al derecho de los particulares o a las leyes $>>$.

En definitiva, si de un lado en el artículo 102 de la ley se establece la posibilidad de proceder a la revisión de oficio sin sujeción a plazo (en cualquier momento), en el artículo 106 se establece la posibilidad de que su ejercicio se modere por la concurrencia de las circunstancias excepcionales que en él se prevén, limitándose la posibilidad de expulsar del ordenamiento jurídico un acto que incurre en un vicio de especial gravedad ponderando las circunstancias de todo orden concurrentes y los bienes jurídicos en juego. Esta previsión legal permite que los tribunales puedan controlar las facultades de revisión de oficio que puede ejercer la Administración, confiriéndoles un cierto margen de apreciación sobre la conveniencia de eliminación del acto cuando por el excesivo plazo transcurrido y la confianza creada en el trafico jurídico y/o en terceros se considera que la eliminación del acto y de sus efectos es contraria a la buena fe o la equidad, entre otros factores.

Ahora bien, la correcta aplicación del art. 106 de la Ley 30/1992, como ya dijimos en la STS n 1404/2016, de 14 de junio de 2016 (rec. 849/2014), exige $<<$ dos requisitos acumulativos para prohibir la revisión de oficio, por un lado la concurrencia de determinadas circunstancias (prescripción de acciones, tiempo transcurrido u "otras circunstancias"); por otro el que dichas circunstancias hagan que la revisión resulte contraria a la equidad, la buena fe, el derecho de los particulares o las leyes $>>$.

Es por ello que la jurisprudencia ha sostenido que <<la decisión última sobre la procedencia o no de la aplicación del art. 106 dependerá del caso concreto y de los bienes jurídicos en juego, comprendiendo el precepto tanto la prescripción tributaria, como la de los derechos y obligaciones originados en el seno de las relaciones entre la Administración y el ciudadano y los derechos adquiridos en las relaciones entre particulares" (STS de 17 de enero de 2006). $Y$ también hemos señalado que este límite opera tan solo cuando "el ejercicio de la facultad de revisión que pretende hacer valer la parte actora se presenta contrario a la buena fe y como tal no merece ser acogida la postura de quien consciente y voluntariamente difiere de forma tan exagerada las posibilidades de reacción que siempre tuvo a su disposición, estando prevista la aplicabilidad de dicho artículo 106 precisamente como adecuado complemento para evitar que la ausencia de un plazo para instar la nulidad pueda ser torticeramente utilizada en actuación contraria a la buena fe $>>$, tal y como señala la STS de 1 de julio de 2008 (rec. 2191/2005).

TERCERO. En el supuesto que nos ocupa, la sentencia de instancia confirmó la Orden de 21 de febrero de 2013 del Consejero de Economía, Innovación, Ciencia y Empleo en lo referente a la revisión de oficio y consiguiente declaración de la nulidad de las ayudas concedidas en su día por la Junta de Andalucía a la empresa, al entender que la subvención se habian otorgado prescindiendo total y absolutamente del procedimiento legalmente establecido. El Tribunal de instancia llega a calificar dicha nulidad de "inequívoca" por no haber existido ni la solicitud de ayuda ni su aceptación y por cuanto la Administración eludió todos los trámites de la Ley General de Subvenciones previstos para su concesión y gestión, afectando dicha nulidad a los posteriores Convenios para materializar el pago. 
La sentencia, sin embargo, invocando razones de seguridad jurídica, aplicó el art. 106 de la Ley 30/1992 y anuló el apartado segundo de dicha Orden en la que se acordaba iniciar el procedimiento para la devolución de las cantidades indebidamente percibidas. A tal efecto, consideró que el plazo de cuatro años de prescripción para la restitución de la ayuda, previsto tanto en la Ley General de Subvenciones (art. 39) como en la Ley General Presupuestaria o la Ley de Hacienda Pública Andaluza, había sido superado desde la fecha del último pago el 5 de junio de 2007, por lo que los efectos de la nulidad declarada debian quedar atemperados.

Varias son las razones por las que no puede compartirse la interpretación y aplicación que del art. 106 de la ley 30/1992 realiza el tribunal de instancia.

1) En primer lugar, porque no es posible asimilar el mero transcurso del plazo de prescripción de las acciones para exigir el reintegro de la subvención con los límites excepcionales que pueden oponerse a las facultades de revisión de oficio de un acto nulo de pleno derecho.

Conviene empezar por recordar que no nos encontramos ante un supuesto de reintegro por incumplimiento, previsto en el artículo 37 de la Ley General de Subvenciones, sino ante la declaración de nulidad de la concesión de la ayuda, (artículo 36.1 a) de la Ley 38/2003, de 17 de noviembre, General de Subvenciones) por concurrir algunos de los motivos de nulidad de pleno derecho contemplados en el artículo 62.1 de la Ley 30/1992. Nulidad que determina conforme el apartado 4 del art. 36 de la ley de Subvenciones la devolución de las cantidades percibidas.

La acción destinada a instar la nulidad de pleno derecho, a diferencia de las acciones para exigir el reintegro, no está sujeta a plazo alguno de prescripción y precisamente por ello el art. 106 de la Ley 30/1992 permite que solo puede impedirse su ejercicio en supuestos excepcionales. Es por ello que el lapso temporal utilizado para el ejercicio de la acción de revisión no se ha identificado con los plazos de prescripción de las acciones frente actos anulables sino que ha recibido una interpretación mucho más restrictiva, reservándose para aquellos supuestos en los que el plazo transcurrido resulta excesivo y desproporcionado afectando a la seguridad juridica generada y muy especialmente cuando afecta a terceros. Normalmente en aquellos casos en los que el lapso de tiempo transcurrido desde que se conocieron las irregularidades o vicios del acto y la actitud de pasividad mostrada desde entonces permite entender que debe primar el principio de seguridad jurídica frente al de legalidad, pues la equidad y buena fe hacen improcedente su revisión. Asi se ha considerado por la jurisprudencia, aplicando la excepción prevista en el art. 106 cuando se ha pretendido la anulación de deslindes aprobados décadas antes de su revisión (SSTS de 21 de febrero de 2006, rec. 62/2003 y de 20 de febrero de 2008 (rec. 1205/2006); o en los casos de anulación de un acuerdo de colegiación instado veinte años después (STS 16-7-2003, sección. 4', recurso 6245/1999), por entender que resulta contraria a la equidad; o cuando habian transcurrido 58 años desde la aprobación del deslinde que se pretendía impugnar (STS de 17 de noviembre de 2008 (rec. 1200/2006) entre otros.

En todo caso, la aplicación de este precepto exige que el tribunal hubiese razonado sobre las razones excepcionales relacionadas con la equidad, buena fe o derechos de los particulares que se verían afectados por la nulidad del acto declarada, sin que la sentencia contenga razonamiento 
alguno al respecto. Antes al contrario, descarta expresamente, y este aspecto no es controvertido en casación, que el cambio de propietarios de la sociedad tenga influencia en el caso de autos. Sin que, por lo tanto, baste con vincular el transcurso del previsto en el ordenamiento jurídico para ejercer la acción de anulación o para solicitar el reintegro, con el límite excepcional previsto en el art. 106 de la Ley 30/1992 para impedir el ejercicio de la revisión de un acto nulo de pleno derecho, pues este razonamiento confunde el plazo de prescripción de la acción para solicitar el reintegro de la subvención por incumplimiento de la misma, con el límite excepcional que opera cuando existe un ejercicio desproporcionado de la facultad de revisión de oficio.

2) En segundo lugar, tampoco puede compartirse el alcance anulatorio pretendido por la sentencia de instancia, que afectó al apartado segundo de dicha Orden en la que se acordaba iniciar el procedimiento para la restitución de la ayuda indebidamente percibida.

Cuando concurren las circunstancias excepcionales previstas en el art. 106 de la Ley 30/92 lo que procede es excluir la revisión y consecuentemente la declaración de nulidad del acto, pero si el Tribunal considera que la acción de revisión ha sido ejercida correctamente y procede declarar la nulidad de pleno derecho del acto en cuestión, lo que no puede es limitar los efectos de la nulidad apreciada desproveyéndola de toda consecuencia jurídica.

Es el ejercicio de la acción de revisión la que puede limitarse ("no pueden ser ejercitadas") por razones excepcionales, sin que los límites a la revisión previstos en el art. 106 de la Ley 30/1992 se extienda, tal como parece entender el tribunal de instancia, a los efectos de la nulidad previamente declarada. Una vez ejercitada esta acción de revisión de oficio y habiendo considerado el tribunal que estaba correctamente ejercida, y consiguientemente que el acto debia declararse nulo de pleno derecho, el art. 106 no permite al tribunal limitar los efectos de la nulidad previamente acordada, el citado precepto no le faculta para ello.

La revisión de oficio de un acto administrativo, acordada por órgano competente y confirmada por un tribunal, que lo declara nulo de pleno derecho, trae como consecuencia que dicho acto no produjo, o no debió hacerlo, ningún efecto jurídico. Específicamente en materia de subvenciones la declaración, judicial o administrativa, de nulidad de una subvención lleva consigo la obligación de devolver las cantidades percibidas, según dispone el artículo 36.4 de la Ley General de Subvenciones, sin que esta consecuencia legal pueda verse modificada por la aplicación del art. 106 de la Ley 30/1992.

Es más, si se considera que el exceso en la actuación de la Administración no se produjo por el ejercicio de la acción destinada a obtener la revisión de oficio del acto sino por el retraso en el ejercicio de la acción destinada a obtener el reintegro de la cantidad indebidamente percibida, la conclusión alcanzada por la sentencia tampoco podría ser aceptada.

En esta hipótesis el cómputo del plazo para que la Administración pudiese ejercer la acción destinada a reclamar las cantidades indebidamente percibidas no puede empezar a computarse sino desde el momento en que la declaración de nulidad es firme, pues solo a partir de ese momento la 
Administración está legitimada para solicitar el reintegro de las cantidades que a la postre se consideraron indebidamente percibidas. Asi lo apuntamos ya, aunque de forma incidental, en nuestra sentencia de 14 de julio de 2015 (rec. 2223/201) afirmándose que $<<[. .$.$] aunque ciertamente$ tiene razón la Administración recurrente en que difícilmente podría correr el plazo de prescripción para reclamar una cantidad cuya percepción ha sido declarada nula de pleno derecho antes de dicha declaración de nulidad $>>$. Sin que tampoco se pueda confundir este supuesto con la prescripción de la acción destinada a reclamar el importe de las subvenciones por incumplimiento de las condiciones que, como ya hemos señalado en una numerosa jurisprudencia, no requiere el ejercicio previo de una revisión de oficio".

El reciente auto de 22-II-2017 (recurso de casación 1934/2014), dictado para desestimar un incidente de nulidad interpuesto por la empresa beneficiaria contra la sentencia, resume la doctrina del Tribunal Supremo acerca de la manera de aplicar el artículo 106 Ley 30/1992 (artículo 110 Ley 39/2015) y en especial cuando se trata de subvenciones.

"1) No es posible asimilar el mero transcurso del plazo de prescripción de las acciones para exigir el reintegro de la subvención con los límites excepcionales que pueden oponerse a las facultades de revisión de oficio de un acto nulo de pleno derecho.

2) Cuando concurren las circunstancias excepcionales previstas en el artículo 106 de la Ley 30/1992 lo que procede es excluir la revisión y consecuentemente la declaración de nulidad del acto, pero si el tribunal considera que la acción de revisión ha sido ejercida correctamente y procede declarar la nulidad de pleno derecho del acto en cuestión, lo que no puede es limitar los efectos de la nulidad apreciada, desproveyéndola de toda consecuencia jurídica.

Una vez ejercitada esta acción de revisión de oficio y habiendo considerado el tribunal que estaba correctamente ejercida, y consiguientemente que el acto debía declararse nulo de pleno derecho, el artículo 106 no permite al tribunal limitar los efectos de la nulidad previamente acordada.

La revisión de oficio de un acto administrativo, acordada por órgano competente y confirmada por un tribunal, que lo declara nulo de pleno derecho, trae como consecuencia que dicho acto no produjo, o no debió hacerlo, ningún efecto jurídico. Especificamente en materia de subvenciones la declaración, judicial o administrativa, de nulidad de una subvención lleva consigo la obligación de devolver las cantidades percibidas".

\section{Examen de los límites de la buena fe y del principio de confianza legítima.}

La sentencia de 11-V-2017, a la que ya se ha hecho referencia por otras razones, dedica buena parte de su fundamentación a examinar si en el caso enjuiciado la revisión de oficio sería contraria a la confianza legítima, a la equidad o a la buena fe. 
El examen comienza relacionando las omisiones del expediente de concesión de la subvención que en el mismo se advierten. FD Duodécimo: "El concepto mismo de la subvención es incompatible con la atribución libérrima de fondos públicos. En ningún caso puede concebirse la subvención como desplazamiento patrimonial sin causa o con fundamento en la mera liberalidad de la entidad concedente. El instituto jurídico subvencional se inscribe en la actividad de fomento de la Administración, y tiene como fin impulsar u orientar comportamientos para la consecución de objetivos dignos de protección y estímulo, siempre sobre la inexcusable premisa que obliga a la Administración a servir con objetividad los intereses generales (art. 103.1 CE) y a satisfacer las necesidades públicas. (...) es de todo punto inconcebible una subvención ayuna de causa que la justifique y de procedimiento que asegure la tutela de los fines perseguidos. (...) Precisamente el procedimiento, que en el presente expediente de subvención luce por su ausencia, es la garantía fundamental de que las subvenciones se otorgan con objetividad y con sometimiento pleno a la Ley y al Derecho (103.1 de la CE), pues de otro modo podrían propiciarse actuaciones abusivas, arbitrarias, fraudulentas y hasta delictivas, exentas de controles.

Las reglas básicas del procedimiento administrativo, destacadamente la necesidad de que se produzca una solicitud formal de quien pretende obtener la subvención, con todos los requisitos, las bases de la convocatoria, los compromisos que debe asumir la beneficiaria, la fiscalización del gasto, y la propia resolución administrativa que aprecie las razones de utilidad pública e interés social que justifiquen la subvención, han sido omitidas por completo en la sustanciación del expediente de subvenciones que benefició a la actora".

A continuación la sentencia aborda un argumento recurrente de las beneficiarias en sus demandas y recursos, en concreto que han llevado a cabo inversiones en una actividad industrial en la confianza legítima de que la misma se consideraba de interés por la Administración.

A este argumento la sentencia responde de manera rotunda diciendo que hay que analizar el caso concreto para concluir si en efecto se ha podido suscitar una confianza legítima y, tras haber apreciado las omisiones esenciales del procedimiento de concesión de las subvenciones que en la misma se relatan, la sentencia concluye que las mismas evidencian la imposibilidad de haberse suscitado confianza legítima alguna argumentando que: "ningún operador jurídico y económico podría atribuir la menor apariencia de regularidad a un modo de actuar por el órgano administrativo carente de todo procedimiento regular, ni es admisible sostener, como pretende la recurrente, que existía apariencia de ejercicio normal de competencias propias por el Director General de Trabajo y Seguridad Social de la funta de Andalucía, Sr. Guerrero, cuando en las distintas comunicaciones que la empresa recurrente mantiene con el mismo y de las que queda constancia en el expediente, aparecen continuas menciones a la tarea de facilitación del Sr. Guerrero, y que los compromisos que se dicen adquiridos por el mismo lo son con base en meras conversaciones, teniendo en cuenta el nulo alcance vinculante 
del Protocolo de 10 de abril de 2001 y las genéricas intenciones que se atribuyen respectivamente los firmantes de aquel documento".

Pero es que además descarta que se haya podido generar la confianza legítima del beneficiario atendiendo a otras circunstancias que se conocen como la de haber obtenido otras subvenciones de manera regular o su experiencia e implantación en el mercado: "No ha existido, en este caso, ningún elemento que permita apreciar una actividad administrativa normal, que pudiera ser generadora de tal expectativa legitima. Antes bien, la actora, que muestra el conocimiento propio de un operador jurídico y económico de implantación, no ya regional, sino nacional, no pudo legítimamente considerar que el procedimiento seguido cumpliera con los mínimos requisitos habituales (...) La recurrente acredita con ello que conoce, como no puede de ser de otra manera por su nivel de implantación en el mercado, cómo son los procedimientos de subvención, por lo que no puede declararse defraudado en ninguna legítima expectativa por la revisión de oficio de unas actuaciones administrativas que le han proporcionado subvenciones millonarias, sin haber seguido ninguno de los trámites ni acreditado los requisitos que le constan como trámites habituales en la actividad de fomento de la Administración". Pero es que además tiene en cuenta para descartar toda confianza legítima la gravedad de las omisiones que: "el origen ilícito o gravemente irregular de la actuación administrativa, y la absoluta indefinición de los compromisos o actuaciones que debería desarrollar la beneficiaria de la subvención, es por completo incompatible con el nacimiento de una expectativa legítima digna de protección".

\section{GONGLUSIÓN.}

Las sentencias del Tribunal Supremo comentadas han obligado a cambiar el criterio de la Sección $1^{\text {a }}$ de la Sede de Sevilla de la Sala de lo contencioso-administrativo del TSJA acerca de la ampliación del plazo para resolver al amparo del artículo 49 de la Ley 30/1992 y de los límites a la revisión de oficio en el caso de las revisiones de oficio de subvenciones investigadas en la causa de los ERE.

Sin embargo, situando estas sentencias en su contexto, desde febrero de 2014, en que recayó la primera de las sentencias sobre revisión de oficio hasta diciembre de 2016, en que se pronunció el Supremo por primera vez, han sido muchas las sentencias que han sido dictadas por la Sala del TSJA. Ello significa que en los casos en los que se declaró la caducidad se puede tramitar un nuevo expediente de revisión de oficio que permite aún recuperar las subvenciones pero con el riesgo de que por cualquier motivo su recuperación resulte ya imposible por extinción de la empresa, insolvencia u otra causa dado el tiempo tranascurrido. Por su parte, en el caso de aquellas otras sentencias que se siguieron dictando con arreglo a la interpretación del artículo 106 Ley 30/1992 que ha mantenido la Sala hasta que se ha pronunciado el Tribunal Supremo los beneficiarios de subvenciones inferiores a 600.000 euros 
(límite cuantitativo de la casación hasta la Ley Orgánica 7/2015) declaradas judicialmente nulas de pleno derecho no tendrán que devolverlas.

Por esta razón, una vez firmes la sentencias recaídas en el orden contencioso-administrativo, la recuperación de las subvenciones indebidamente percibidas depende ahora de la jurisdicción contable o del resultado de la causa penal, en este último caso suponiendo que sus beneficiarios se encuentren aún en la condición de investigados pues no debe olvidarse que la dilatada instrucción que aún no ha terminado ha motivado que en algunos casos los delitos se han declarado ya prescritos.

Ante esta situación, las sentencias del Tribunal Supremo dictadas hasta el momento constituyen un indudable estímulo para la aplicación de las normas del derecho administrativo pues demuestran que es posible el resarcimiento a través de una de las vías ordinarias reconocidas por el ordenamiento a la Administración en virtud del privilegio de autotutela como es la de la revisión de oficio, reforzada en este caso por el artículo 36. 4 de la Ley General de Subvenciones.

Estas sentencias del Tribunal Supremo demuestran que el ordenamiento administrativo cuenta con mecanismos resarcitorios en casos como el que nos ocupa y que las lagunas que se presentaban en las sentencias revocadas tenían soluciones en el ordenamiento jurídico español.

En materia de subvenciones no puede confiarse al resultado de la causa penal (última ratio) la recuperación de unos fondos públicos que se podían haber restituido a través de las vías ordinarias como la de la revisión de oficio de actos que, por ser nulos de pleno derecho, no tiene plazo de prescripción. 